\title{
Physiochemical Comparism of Three Different Types of Soft Cheese
}

\author{
Felix O Enwa ${ }^{1 *}$, John A Avbunudiogba ${ }^{2}$ and Omojate C Godstime ${ }^{3}$ \\ ${ }^{I}$ Department of Pharmaceutical Microbiology, Faculty of Pharmacy, Delta State University, Abraka, Nigeria. \\ ${ }^{2}$ Department of Pharmaceutics and Pharmaceutical Technology, Delta State University, Abraka, Nigeria. \\ ${ }^{3}$ Department of Pharmaceutical Chemistry, Faculty of Pharmacy, Delta State University, Abraka, Nigeria.
}

\begin{abstract}
The escalating cost and the incidence of untoward effects associated with the use medicines of allopathic origin make the consumers incline towards alternative therapeutic agents. As dietary supplements are the most consumers' acceptable therapeutic agents used to mitigate malnutrition-induced diseases, this study was carried out to develop a symbiotic soft cheese. The Soft cheese was manufactured using substrates or starter cultures under standard physico-chemical and microbiological conditions. The moisture content, the $\mathrm{pH}$ values, acidity, as well as the bacteriological and organoleptic properties during storage of the soft cheese produced were evaluated. The results revealed that there was no significant difference $(p<0.05)$ in all the properties of soft cheese evaluated. The results obtained from this research revealed that the soft cheese produced under standard physico-chemical conditions such as temperature, acidity, humidity and $\mathrm{pH}$, and microbiological conditions such as the addition of starter cultures as well as Penicillium camemberti, could be a promising high quality nutraceutical for the treatment of malnutrition-induced diseases.
\end{abstract}

Keywords: Starter cultures, Nutraceuticals, Soft cheese, Whey, Rennet.

\section{Introduction}

The commercial interest in functional foods containing probiotic microbial strains has consistently increased due to the awareness of the benefits for gut health, pathologic prophylaxis as well as therapy [4]. Modern consumers expect their food to be healthy so as to ensure the prophylaxis of illnesses as well as the maintenance of the global health security [9]. This explains the reason for a rising interest in probiotic healthbased products. Probiotic products are important functional foods as they represent about $65 \%$ of the world functional food market [1]. Probiotic bacteria have been utilised as additives to an array of foods, most importantly, dairy products such as yogurt, cheese, ice cream, as well as dairy desserts. They are sometimes added to non-dairy products such as chocolate, cereals, juices [2]. Foods containing probiotic bacteria are categorized as "functional foods" and such products are gaining widespread popularity and acceptance because they have therapeutic benefits which include the treatment of diarrhoea, alleviation of symptoms of lactose intolerance, improvement in immunity, anticarcinogenic properties, as well as the management of dyslipidaemia [15]. In bid to elicit their nutraceutical effects, probiotic bacteria need, firstly, to survive during the manufacturing process physicochemical conditions and that of the upper gastrointestinal ecosystem. The ability of probiotic strains to survive passage through the GI tract can be mainly attributed to their acid and bile tolerance. These are intrinsic properties of the strain, which can be improved by the protective action of carrier foods [5] and/or by the presence of nutrients such as prebiotics [6]. The most common food matrices used as probiotic vehicles are dairy products, which are able to enhance the transit tolerance of bacteria. Cheese is a dairy product which has a good potential for delivery of probiotic microorganisms into the human intestine due to its physicochemical properties compared to fermented milks (higher $\mathrm{pH}$ value and lower titratable acidity, higher buffering efficiency, greater fat content, higher nutrient availability, lower oxygen content and denser matrix of the texture). To be considered to offer probiotic health benefits, probiotics must remain viable in food products above a threshold level (e.g., $10^{6} \mathrm{CFU} / \mathrm{g}$ ) until the time of consumption [10]. In fact, cheese provides a valuable alternative to fermented milks and yogurts as a food vehicle for probiotic delivery, due to certain potential advantages. It creates a buffer against the high acidic environment in the gastrointestinal tract and thus creates a more favourable environment for probiotic survival throughout the gastric transit, due to higher $\mathrm{pH}$. Moreover, the dense matrix and relatively high fat content of cheese may offer additional protection to probiotic bacteria in the stomach [3][7][14].

The true origin of cheese is a mystery. Sheep and cattle were domesticated in Egypt and Mesopotamia so many years ago and the Old Testament refer to it as 'Cheese of kine'. The basic principle for cheese making remain the same and production process can be referred to as a dehydration process since there is the draining away of the whey. The conversion of milk to cheese involve several distinct but interrelated processes including coagulation, acidification, synthesis (separation of the whey from the cheese), dehydration, moulding, pressing 
and salting. Cheese is the concentrated form of milk containing most of calcium, protein, fat and vitamins, which are needed by man for the development of strong bones and for healthy living.

Cheese is a concentrated source of many of the nutrients in milk. During the usual cheese making process, the water insoluble components of milk e.g. the milk protein - casein and fat, remain in the curd and the water soluble constituents e.g. carbohydrates, salts, and proteins smaller than casein, remain in the whey. The amount of various nutrients retained in the curd and whey depends on the type of cheese manufactured, the type of milk used and the manner of coagulation. The enzymes and bacteria involved in ripening of each specific kind of cheese may also alter the nutrient content of the end product.

It is the purpose of this research to examine the fundamental techniques involved in the manufacture of soft cheese which encompasses both the physico-chemical and microbiological changes that take place during production.

\section{Materials and Method}

\section{Materials}

- Pasteurizer

- Buckets

- Thermometer

- Calibrated bucket

- Stirrer

- Cheese Knife

- Weighing equipment

- Straw mat and board

- Acidometer or $\mathrm{NaOH}(0.11)$ and Phenolophthalein.

- Coulommiers moulds

- Steam sterilizer

- $\mathrm{pH}$ meter

- mould spores

\section{Method:}

The procedure for the production of soft cheese as described in the fermentation Practical handbook [12], is shown below.

III. PRODUCTION OF SOFT CHEESE

RAW MILK

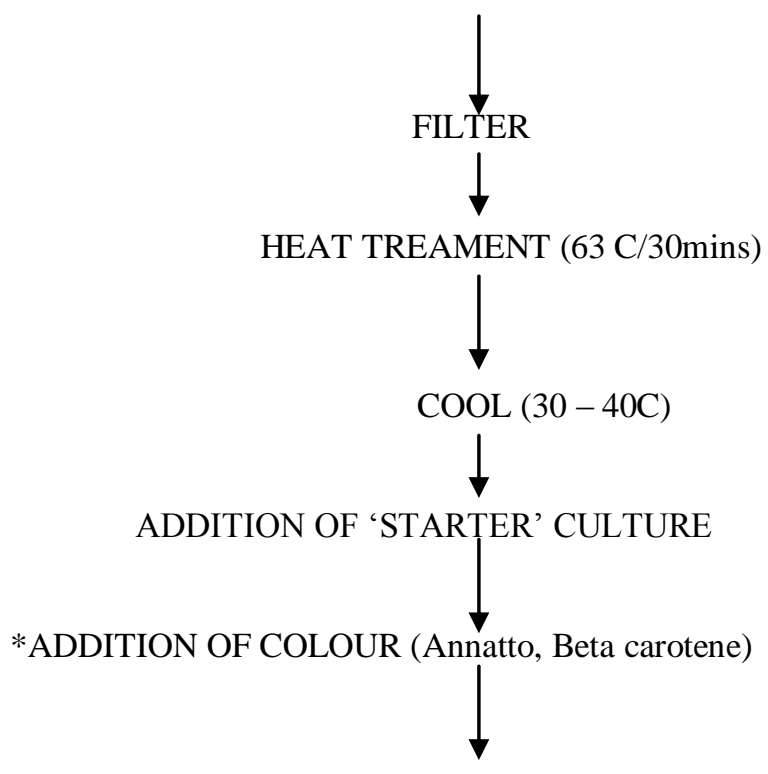

*ADDITION OF MOULD SPORES (P. camemberti) 
INCUBATION $\left(30^{\circ} \mathrm{C} / 40-45 \mathrm{~min}.\right)$

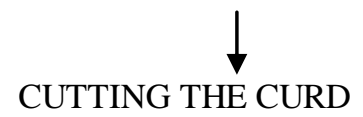

DRAINAGE OF WHEY
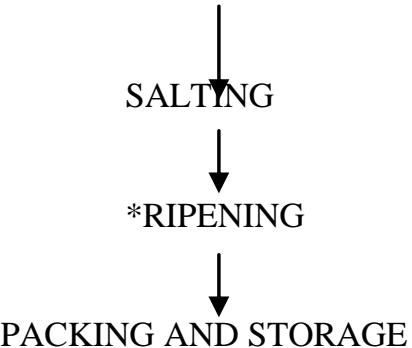

Key:

- - optional steps

\begin{tabular}{|c|c|c|c|}
\hline \multicolumn{4}{|c|}{ RESULT } \\
\hline Requirement & Coulomier & Camembert & Lactic \\
\hline Milk quantity (L) & 5litre & 5litre & 5litre \\
\hline $\begin{array}{l}\text { Milk acidity } \\
\text { lactic acid }\end{array}$ & 0.19 & 0.19 & 0.19 \\
\hline Milk pH & 6.65 & 6.65 & 6.65 \\
\hline $\begin{array}{l}\text { Pasteurisation temp. } \\
\text { /time }\end{array}$ & $63^{\circ} \mathrm{C} / 30 \mathrm{~min}$ & $63^{\circ} \mathrm{C} / 30 \mathrm{~min}$ & $63^{\circ} \mathrm{C} / 30 \mathrm{~min}$ \\
\hline $\begin{array}{l}\begin{array}{l}\text { Cheese milk temp. } \\
\left({ }^{\circ} \mathrm{C}\right)\end{array} \\
\end{array}$ & $32^{\circ} \mathrm{C}$ & $32^{\circ} \mathrm{C}$ & $32^{\circ} \mathrm{C}$ \\
\hline $\begin{array}{l}\text { Quantity of starter } \\
\text { (ml) }\end{array}$ & $3 \mathrm{ml}$ & $4 \mathrm{ml}$ & $40 \mathrm{ml}$ \\
\hline Time of inoculation & $11.45 \mathrm{am}$ & $11.45 \mathrm{am}$ & $11.45 \mathrm{am}$ \\
\hline $\begin{array}{l}\text { Quantity of rennet } \\
\text { added }(\mathrm{ml})\end{array}$ & $4 \mathrm{ml}$ & $4 \mathrm{ml}$ & - \\
\hline $\begin{array}{ll}\text { Inoculation temp. } \\
\left({ }^{\circ} \mathrm{C}\right)\end{array}$ & $32^{\circ} \mathrm{C} / 45 \mathrm{mins}$ & $32^{\circ} \mathrm{C} / 45 \operatorname{mins}$ & $25^{\circ} \mathrm{C} / 24 \mathrm{hrs}$ \\
\hline $\begin{array}{l}\text { Acidity of moulding } \\
(\%)\end{array}$ & 0.37 & 0.37 & 0.76 \\
\hline $\mathrm{pH}$ of moulding & 6.53 & 6.53 & 4.32 \\
\hline $\begin{array}{l}\text { Temp. Of moulding } \\
\left({ }^{\circ} \mathrm{C}\right)\end{array}$ & $31{ }^{\circ} \mathrm{C}$ & $31{ }^{\circ} \mathrm{C}$ & $22^{\circ} \mathrm{C}$ \\
\hline $\begin{array}{l}\text { Acidity of whey @ } \\
\text { day } 2\end{array}$ & $0.94 \%$ & $0.51 \%$ & $0.8 \%$ \\
\hline pH of cheese@ day 2 & 4.82 & 4.31 & 4.10 \\
\hline pH of cheese@ day 3 & 4.29 & 4.17 & 4.13 \\
\hline Quantity of salt & $5 \mathrm{~g}$ & $\begin{array}{l}\text { Soak in } 20 \% \text { brine } \\
\text { for } 30 \text { mins. }\end{array}$ & $10 \mathrm{~g} / \mathrm{kilo}$ of curd \\
\hline
\end{tabular}


Chart. 1 Acidity of moulding of the soft cheese types

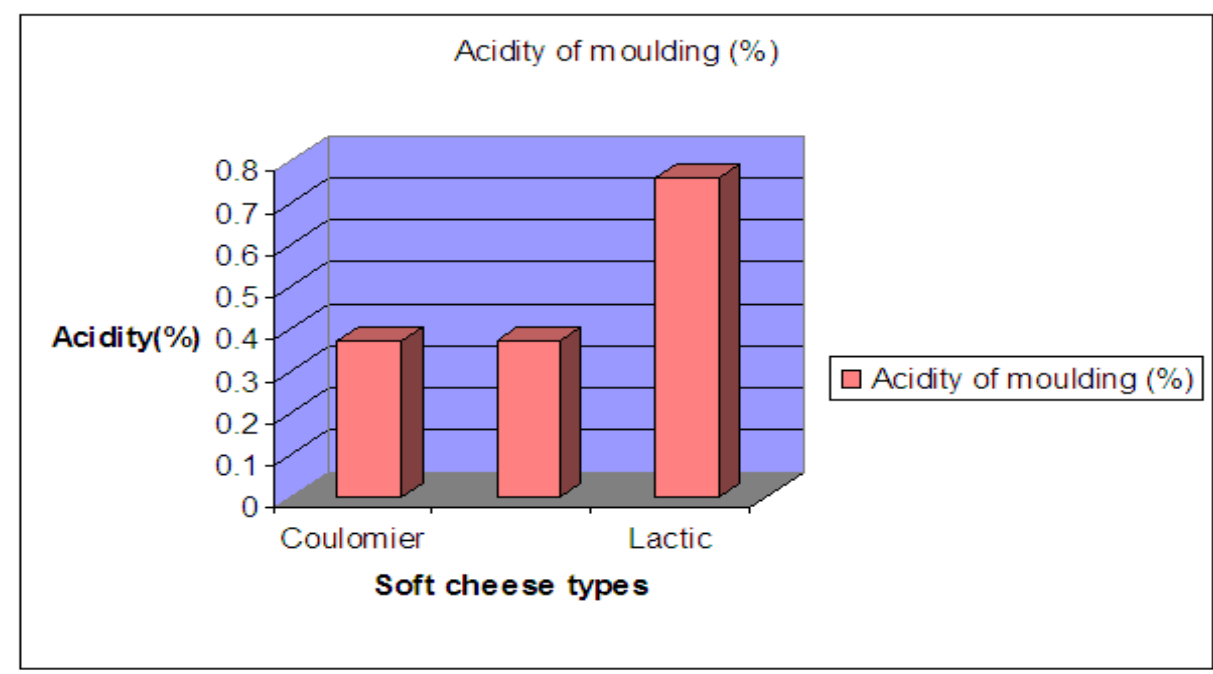

Chart. 2 pH of moulding of the different soft cheese types
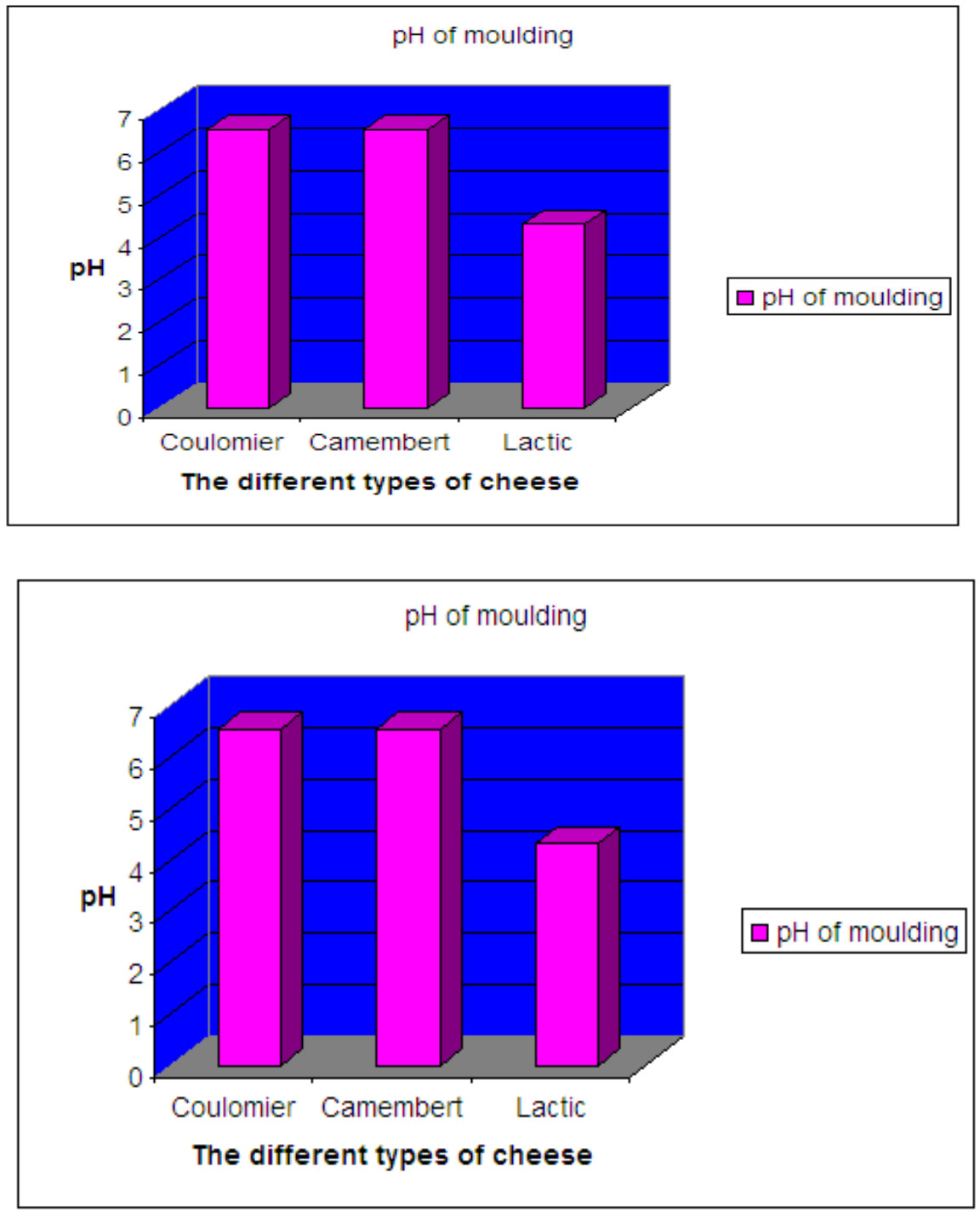
Chart. 3 Acidity of whey at day two (2)

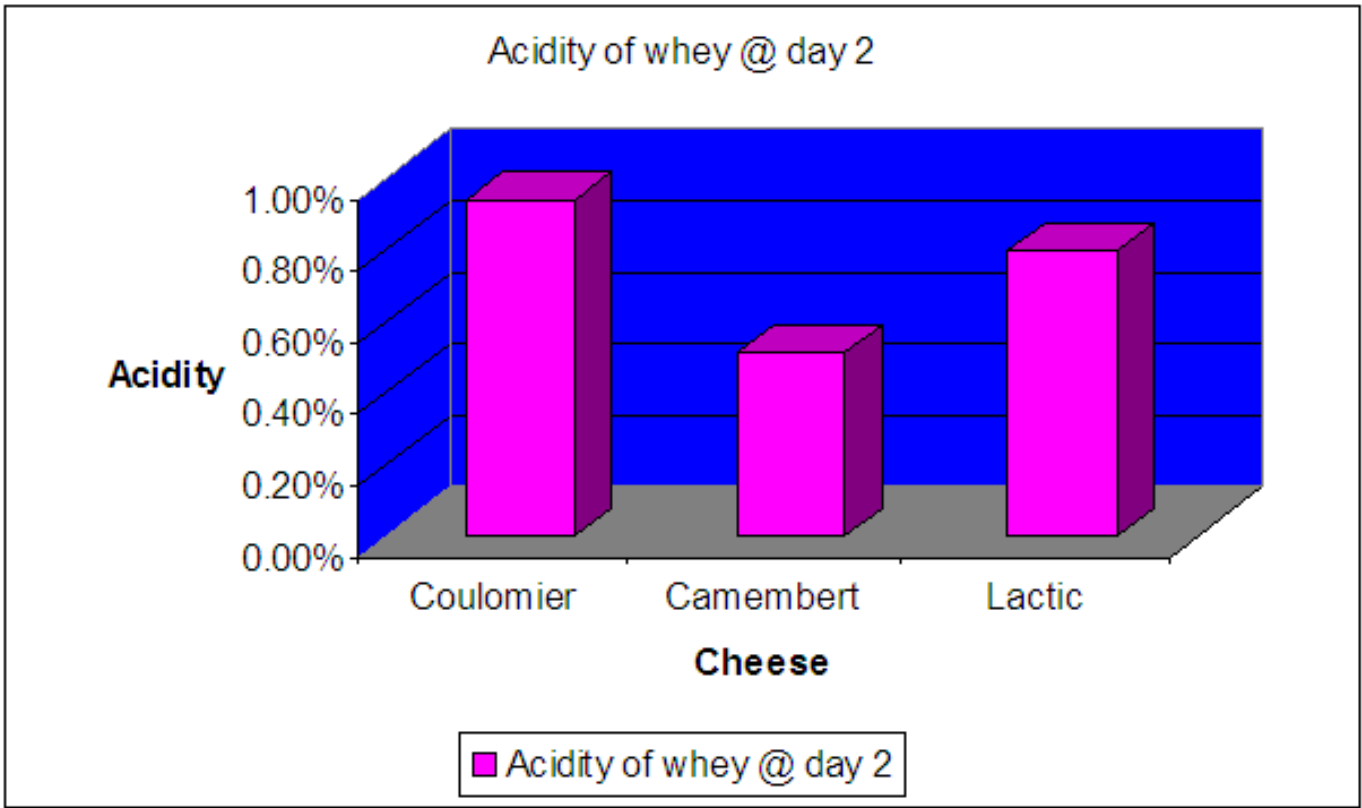

Chart. $4 \mathrm{pH}$ of cheese at different days

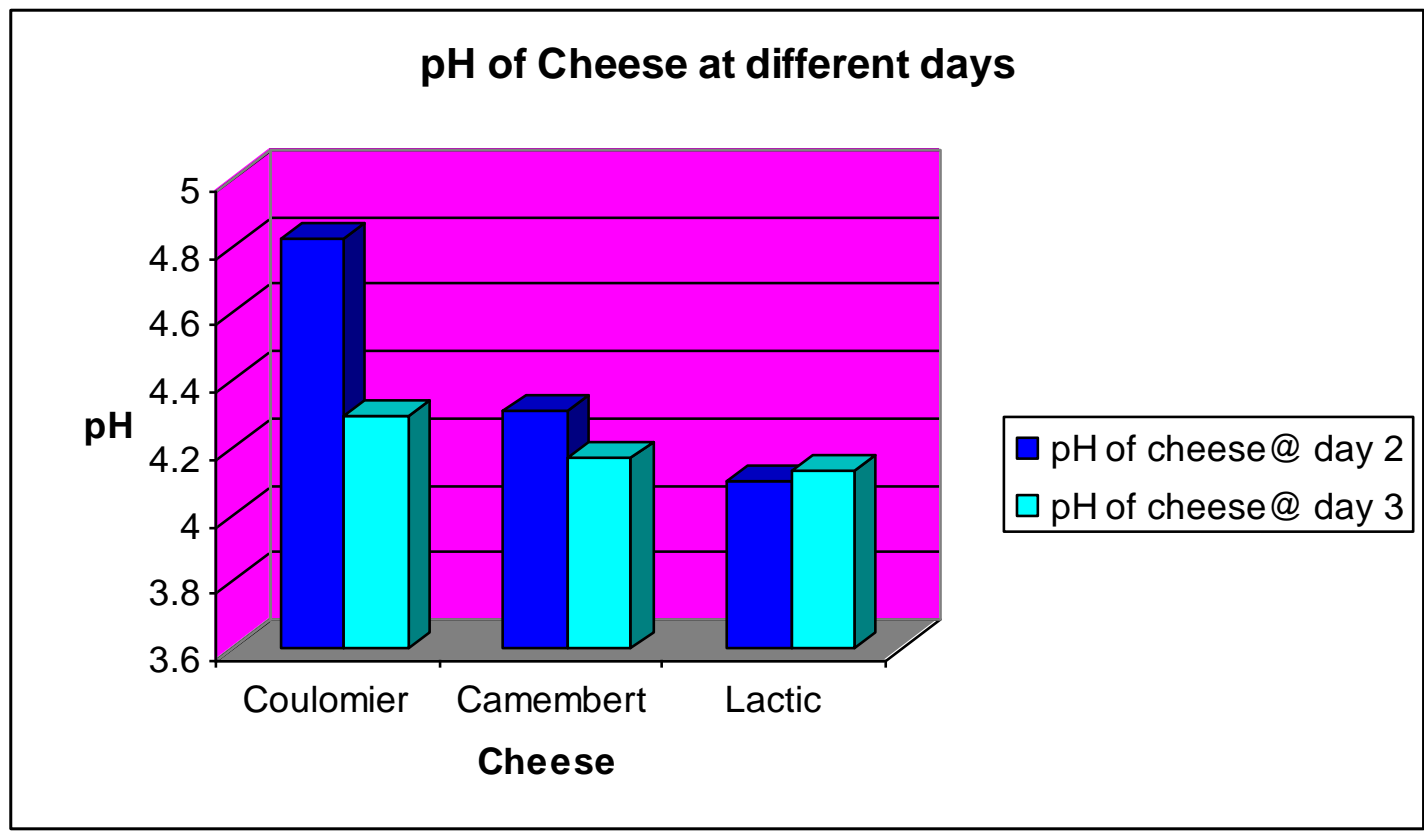

\section{Discussion}

The basic principles involved in the manufacture of cheese have remained the same for over decades. The milk is firstly heat-treated to kill off any harmful bacteria that may be present. Starter cultures of special bacteria are then added to the milk and their growth "ripens" the milk and helps to develop the desired flavours and aromas. Rennet is then added to the milk which helps it to coagulate and turn into curds and whey. Rennet was traditionally extracted from calves stomachs, but is now artificially produced from vegetarian sources. The curds and whey are then heated to a high temperature and salt is added to produce the correct texture and flavour. The cheese is then pressed to force out the whey, and to give it its final shape. The cheese is then left to mature and the longer the cheese is left in storage the more mature the flavour becomes.

Soft cheeses fall into two categories; ripened soft cheese such as brie and fresh cheese and unripened cheese such as cottage cheese. Soft cheeses are made from heat treated milk which is fermented by the use of specific bacteria. Artificial rennet is sometimes used to produce a firmer texture. Fresh cheeses are ready for use as soon as the manufacturing process is complete but ripened cheeses are allowed to mature in temperature and humidity controlled rooms for up to one month. 
In the production of cheese, the moisture content of cheese serves as the first term to distinguish various categories. The fat content is the second term, and the curing characteristics represents a third term. These three terms apply to all cheeses covered by the A6 Standard under Codex Alimentarius. However, this classification does not preclude the designation of more specific requirements in individual cheese standards. Another thing to note is the starter culture, which is a very important factor in cheese production.

Mesophilic cultures with optimum growth temperature of $20-35^{\circ} \mathrm{C}$ for cheese milk conditioned at moderate temperature and thermophilic cultures for cheese milk conditioned at relatively high temperature are ideal. Mixed cultures are often used to achieve maximum aroma and flavour development. The criteria for a starter culture are it's ability to form lactic acid in a short time, the ability to cause proteolysis during ripening of the cheese and the ability to produce carbon dioxide for some cheese varieties.

From this research, it was observed that the aim of cheese making is to obtain a curd with defined moisture content. This is achieved by a controlled expulsion of whey from the curd particles [8\}. The cutting of the curd is done to facilitate whey expulsion by creating a much greater surface for drainage. Stirring of the curd also promotes whey drainage by the mechanical action and by preventing the particles from adhering to one another. In cheese as in many other foods, salt normally functions as a condiment. However, salt has other important effects, such as retarding starter activity and microbial processes associated with cheese ripening. The application of salt to the cheese block causes more moisture to be expelled, both through osmotic effects and a salting-out effects on the proteins. The Dairy Processing Handbook cites the following information from the Danish Dairy Research Institute (Report No. 22) that the criss-crossing of cheese curd by capillaries yields approximately 10,000 per cc.

There are several factors that can affect the permeability of the capillaries and the ability of the salt solution to flow through them. For instance, since fat globules may block some of the capillaries, salt penetration might be impaired in the production of cheese of high fat content. The $\mathrm{pH}$ at the time of salting has considerable influence on the rate of salt absorption. More salt can be absorbed at low $\mathrm{pH}$ than at higher $\mathrm{pH}$. However at low $\mathrm{pH}(<5.0)$, the body of the cheese is hard and brittle. At higher $\mathrm{pH}(>5.6)$, the body remains elastic. From chart 2, the $\mathrm{pH}$ of Coulomier and Camembert is 6.53 for both except for lactic cheese, which is 4.32. It was observed that loosely bound calcium is sensitive to $\mathrm{pH}$ changes; the lower the $\mathrm{pH}$ the more calcium will be sequestered from the paracasein complex. This might be attributable to the protonation of hydrogen ions on the calcium sites. If the $\mathrm{pH}$ of cheese curd before salting is in the high range (6.0-5.8), a considerable amount of calcium is still present in the paracaeinate, which is to say for coulomier and Camembert have some considerable amount of casein, while that of the lactic cheese shows that casein had been removed. At the $\mathrm{pH}$ range 5.2-5.6, there is an ionic balance between the calcium ions and hydrogen ions to bind the optimum amount of sodium to provide for a satisfactory body and texture.

Fully ripened Camembert cheese is characterized by a mild aroma and a soft, spreadable consistency. An over-ripe cheese has a characteristic choking smell like that of ammonia and volatile fatty acids. During ripening, growth of a white mould ( $P$. camemberti) is encouraged on the surface. This aerobic organism produces both protease and lipase enzymes which penetrate the surface into the cheese.

Comparing the three types of cheese produced in this research, it was also observed that there was no significant difference $(\mathrm{P}$-value $<0.05)$ in the $\mathrm{pH}$ level at day 1 between coulomier and camembert. This may probably be due to the fact that the starter culture has not started its fermentation activity at that time and the rennet might have also contributed as well. In converse, the lactic cheese had a low $\mathrm{pH}$ which could be attributed to the non addition of rennet. In chart 4, the $\mathrm{pH}$ of coulommier was highest followed by Camembert for both day 2 and day 3 which may be liken to the microbial activity within each products. The reason for the low $\mathrm{pH}$ in camembert could be as result of mixed fermentation from both bacterial starter culture and the Penicillium mould that was added. The lactic cheese was the lowest could be attributed to the way it was allowed to ferment without the addition of rennet or Penicillium mould which could influence the fermentation process. Nevertheless, the three category of cheese were suitable for consumption, lactic cheese present a very sharp taste and smell compared to the other two cheese and also camembert was the most preferred because of the mould that grew over it and the slimy nature when cut.

\section{Conclusion}

The fundamental techniques involved in the manufacture of soft cheese which encompasses both the physicochemical and microbiological changes that take place during production were evaluated. The results obtained from this research revealed that the soft cheese produced under standard physico-chemical conditions such as temperature, acidity, humidity and $\mathrm{pH}$, and microbiological conditions such as the addition of starter cultures as well as $P$. camemberti, could be a promising nutraceutical for the treatment of malnutrition-induced diseases. 


\section{Acknowledgement}

The authors are grateful to the omniscient God for being their source of knowledge, strength and inspiration

\section{Reference}

[1] Agrawal, R. (2005). Probiotics: an emerging food supplement with health

[2] Anal A.K., Singh, H. (2007). Recent advances in microencapsulation of delivery. Trends Food Science and Technology, 5(18): 240-251.

[3] Bergamini C., Hynes V., Quiberoni E.R., Suarez A., Zalazar C. A., (2005).

[4] Chapman C., Gibson M., Rowland G.I., (2011). Health benefits of probiotics: strains. European Journal of Nutrition, 1(50):1- 17.

[5] Charalampopoulos D., Pandiella S.S., Webb C., (2003). Evaluation of the effect of malt, wheat and barley extracts on the viability of potentially probiotic lactic acid bacteria under acidic conditions. International of Food Microbiology, 1(82): 133 - 141.

[6] Corcoran B., Stanton M., Fitzgerald C.G. F., Ross R.P., (2005). Survival of probiotic lactobacilli in acidic environments is enhanced in the presence of metabolisable sugars. Applied Environmental Microbiology, 8 (71): $3060-\quad 3067$.

[7] Effat B. A., Mabrouk A. M., Sadek Z. I., Hussein G. A., Magdoub M. N., ( 2012). Production of Novel Functional White Soft Cheese, Journal of Microbiology, Biotechnology and Food Sciences, 1 (5): 1259-1278.

[8] Glynn, C. (1977). Cheese and cheese making. Macdonald Education Ltd, london. 4 - 32.

Kailasapathy K., (2009). Encapsulation technologies for functional foods and nutraceutical product development. CAB Reviews: Perspectives in Agriculture, Veterinary Science. Nutrition and Natural Resources, $33(4): 1-19$.

[9] Karimi R., Mortazavian A. M., Cruz A.G., (2011). Viability of probiotic microorganisms in cheese during production and storage: a review. Dairy Science and Technology, 2(91): 283-308.

[10] Kathy Blis (1988). Practical Cheesemaking. The Crowood press, Ramsbury UK, ISBN 1-85223-023-1.

[11] Kuri V., (2003). Fermentation Practical; food 503 Developments in Food Microbiology, University of Plymouth, Newton Abbot.

[12] Ogilvy S., (1977). Making cheeses. B.T. Batsford Ltd, London,ISBN 0713431687.

[13] Sharp M. D., Mcmahon D.J., Broadbent J.R., (2008). Comparative evaluation of yogurt and low-fat Cheddar cheese as

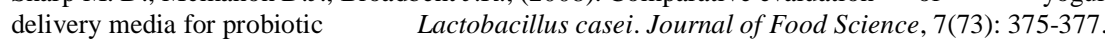

[14] Vasiljevic T., Shah, N. B., (2008). Probiotics - From Metchnikoff to bioactives. International Dairy Journal, 5(18): 714- 728. 